\title{
Silencing of the receptor-like cytoplasmic kinase gene TaRKL1 reduces photosynthetic capacity in wheat
}

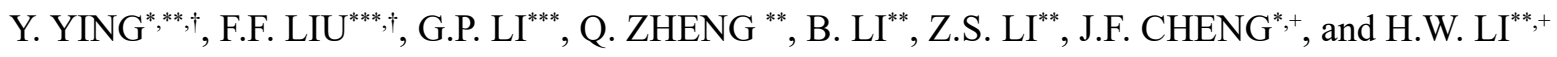 \\ College of Agronomy, Jiangxi Agricultural University, 330045 Nanchang, Jiangxi, China* \\ State Key Laboratory of Plant Cell and Chromosome Engineering, Institute of Genetics and Developmental Biology, \\ Innovative Academy of Seed Design, Chinese Academy of Sciences, 100101 Beijing, China** \\ College of Life Sciences, Huaibei Normal University, 235000 Huaibei, Anhui, China***
}

\begin{abstract}
To explore the role of receptor-like kinases in the regulation of photosynthesis, an uncharacterized TaRKL1 encoding a receptor-like cytoplasmic kinase was investigated in Triticum aestivum cv. Xiaoyan 101 with Barley stripe mosaic virusinduced gene silencing system (BSMV-VIGS). The results showed that the $\mathrm{CO}_{2}$ assimilation rate, stomatal conductance, and transpiration rate were significantly lower in the BSMV:TaRKL1 plants than those in the BSMV: $\gamma 00$ plants (control). Moreover, the maximum photochemical efficiency and electron transport flux decreased while the dissipated energy flux was enhanced in the BSMV:TaRKL1 plants compared to the control. Additionally, the contents of chlorophylls and carotenoids were reduced in the BSMV:TaRKL1 plants. However, the hydrogen peroxide content was significantly enhanced in the BSMV:TaRKL1 plants, which resulted from lower ascorbate peroxidase activity. Consistent with the inhibition of photosynthesis, the transcription levels of the photosynthesis-related, antioxidant enzymes, senescence-associated genes, and four abscisic acid biosynthesis genes were downregulated substantially. Collectively, this study for the first time showed that TaRKL1 regulates photosynthesis and $\mathrm{H}_{2} \mathrm{O}_{2}$ homeostasis. It may be a potential target gene for radiation-use efficiency improvement in wheat.
\end{abstract}

Keywords: $\mathrm{H}_{2} \mathrm{O}_{2}$; photosynthesis; receptor-like cytoplasmic kinases; stomatal conductance; Triticum aestivum L.; virus-induced gene silencing system.

\section{Introduction}

Radiation-use efficiency (RUE) is considered an important approach for the genetic improvement of wheat yield to meet the increasing demand (Horton 2000, Richards 2000). It is a dynamic and complex process regulated by several genes and environmental factors under natural conditions. Identification of genes regulating photosynthesis will provide some target genes for wheat RUE improvement. Receptor-like kinases (RLKs) play crucial roles in the regulation of plant growth, development, hormone signal transduction, and responses to abiotic and biotic stress. $R L K$ s belong to a large gene family and over
600 and 1,131 members were identified in Arabidopsis and rice, respectively (Shiu and Bleecker 2001, Shiu et al. 2004). Generally, a typical RLK protein is composed of an amino-terminal extracellular ligand recognition domain, a transmembrane domain, and a carboxyl-terminal intracellular kinase domain. The extracellular domain perceives intercellular signals or environmental stimuli through binding numerous ligands, such as proteins/ peptides, RNAs, phytohormones, reactive oxygen species (ROS), sugars, nucleotides, polysaccharides, and ions (Liang and Zhou 2018). The intracellular kinase domain propagates and transforms the extracellular signals into cytoplasmic signals and thus regulates the downstream

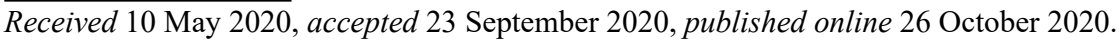

${ }^{+}$Corresponding author; phone: 86-10-64806607, fax: 86-10-64806605, e-mail: chjfkarl@163.com (J.F. Cheng), hwli@genetics.ac.cn (H.W. Li)

Abbreviations: ABA - abscisic acid; APX - ascorbate peroxidase; BSMV - Barley stripe mosaic virus; Car - carotenoids; CAT - catalase; Chl - chlorophyll; $C_{\mathrm{i}}$ - intercellular $\mathrm{CO}_{2}$ concentration; $\mathrm{DI}_{0} / \mathrm{CS}$ - dissipated energy flux per excited cross-section; dpi - days post-inoculation; $E$ - transpiration rate; $\mathrm{ET}_{0} / \mathrm{CS}$ - electron transport flux per excited cross-section; FM - fresh mass; $\mathrm{F}_{\mathrm{v}} / \mathrm{F}_{\mathrm{m}}$ - maximum photochemical efficiency of PSII; $g_{\mathrm{s}}$ - stomatal conductance; LRR-RLK - the leucine rich repeat receptor-like kinases; MDA - malondialdehyde; $\mathrm{PI}_{\mathrm{ABS}}$ - performance index on absorption basis; $P_{\mathrm{N}}$ - photosynthetic rate; POD - peroxidase; qPCR - quantitative polymerase chain reaction; RBOH - respiratory burst oxidase homologs; RLCK - receptor-like cytoplasmic kinases; RLK - receptor-like kinases; RLP - receptor-like proteins; ROS - reactive oxygen species; RUE - radiation-use efficiency; $S A G$ - senescence-associated gene; SOD - superoxide dismutase; TCA - trichloroacetic acid; $\varphi_{\mathrm{Eo}}$ - quantum yield of electron transport from $\mathrm{Q}_{\mathrm{A}}^{-}$to $\mathrm{PQ} ; \Psi_{0}-$ a trapped exciton moves an electron into the electron transport chain beyond $\mathrm{Q}_{\mathrm{A}}^{-}($at $\mathrm{t}=0)$.

Acknowledgment: This work was supported by the Natural Science Foundation of China (31872863 and 31571644).

Conflict of interest: The authors declare that they have no conflict of interest.

These authors contributed equally to this work. 
target proteins. The leucine-rich repeat RLKs (LRRRLKs) represent the largest subfamily of RLKs. For example, a total of 531 TaLRRKs were identified in bread wheat (Shumayla et al. 2016). Receptor-like cytoplasmic kinases (RLCKs), lacking both a transmembrane and an extracellular domain, and receptor-like proteins (RLPs), lacking an intracellular kinase domain, are the variants of typical RLKs and both can interact with RLKs for signal transduction.

The regulation of stomatal aperture determining photosynthesis and transpiration largely is a potential target for wheat RUE improvement. Several lines of evidence showed that a few LRR-RLKs play pivotal roles in the regulation of stomatal development and aperture. In Arabidopsis, the triple mutants of all three $E R$-family genes, ERECTA (ER), ERECTA like 1 (ERL1), and ERECTA like 2 (ERL2) exhibit excessive stomatal clustering (Shpak et al. 2005). Besides, the $E R$ mutants enhance stomatal density and conductance, and thus reduce transpiration efficiency, the ratio of carbon fixation to water loss (Masle et al. 2005). TOO MANY MOUTHS (TMM) encoding an LRR containing RLP (Nadeau and Sack 2002) negatively regulates the three ER-family LRR-RLKs during stomatal development (Shpak et al. 2005). A recent study demonstrated that MUSTACHES enforce stomatal bilateral symmetry in Arabidopsis (Keerthisinghe et al. 2015). Additionally, BRI1-associated receptor kinase 1 (BAK1) was found to regulate ABA-induced stomatal closure in guard cells (Shang et al. 2016). In rice, an ER homologous gene $O S S I K 1$ was found to regulate leaf stomatal density and drought and salt tolerance (Ouyang et al. 2010). In wheat, two ER homologous genes, TaER-D1 and TaER-B1 were isolated, which were induced by drought, salinity, cold, and heat stress (Huang et al. 2013). However, up to now, no wheat RLKs were characterized in the regulation of stomatal development or stomatal closure.

ROS including superoxide anion $\left(\mathrm{O}_{2}{ }^{-}\right)$, hydrogen peroxide $\left(\mathrm{H}_{2} \mathrm{O}_{2}\right)$, singlet oxygen $\left({ }^{1} \mathrm{O}_{2}\right)$, and hydroxyl radical $\left(\mathrm{HO}^{\circ}\right)$ are not only the toxic byproducts of physiological metabolism but also play the roles of signal molecules to regulate stomatal closure. Pieces of evidence demonstrated that $\mathrm{H}_{2} \mathrm{O}_{2}$ acts as a signal molecule in abscisic acid (ABA)-induced stomatal closure (Song et al. 2014). The photosynthetic electron transport chain in chloroplasts is the main source of ROS production (Asada 1999, Foyer and Noctor 2003). Recently, Iwai et al. (2019) reported that guard cell photosynthesis regulates ABAinduced stomatal closure through the ROS generated from the photosynthetic electron transport chain in guard cells which acts as signal molecules in ABA-induced stomatal closure. Besides, a few RLKs work at the upstream of ROS signaling and play a central role in controlling ROS production through phosphorylation and activation of respiratory burst oxidase homologs (RBOHs), a source of apoplast ROS (Kimura et al. 2017). It is important for the normal growth of plants to maintain a low ROS concentration through enhancement of ROS removal capability. For instance, in rice, OSSIK1 not only regulates stomatal density but also enhances the activity of ROS removal enzymes including peroxidase (POD), superoxide dismutase (SOD), and catalase (CAT) and reduces $\mathrm{H}_{2} \mathrm{O}_{2}$ accumulation in leaves of OSSIK1-overexpressing plants (Ouyang et al. 2010). Additionally, a rice RLCK (STRK1) can phosphorylate and activate CatC and thereby improve CAT activity and reduce $\mathrm{H}_{2} \mathrm{O}_{2}$ accumulation. The STRK1 overexpressing plants improve the adaptation to salt and oxidative stress, which provides an opportunity to improve rice yield under saline conditions (Zhou et al. 2018). However, a mutant of LMM24 encoding OsRLCK109 not only enhanced ROS accumulation and cell death but also suppressed the expression of photosynthesis-related genes and enhanced the expression of senescence-associated genes (SAGs), suggesting that OsRLCK109 regulates cell death and defense responses (Zhang et al. 2019). A very recent study demonstrated that an $L R R-R L K$ gene, $O S S R L K$, regulates dark-induced leaf senescence and is involved in chlorophyll degradation (Shin et al. 2020). Therefore, RLKs play diverse roles in the regulation of stomatal development and closure, ROS signaling, cell death, and leaf senescence, and thus possibly may regulate photosynthesis. However, up to now, no reports were found for RLKs regulating carbon assimilation in plants, especially in wheat.

Barley stripe mosaic virus (BSMV), consisting of a single-stranded, tripartite RNA genome $(\alpha, \beta$, and $\gamma)$, is an effective genetic tool for gene function study in barley and wheat (Hein et al. 2005, Scofield et al. 2005). BSMV mediated virus-induced gene silencing (BSMV-VIGS) has been widely used for function study of wheat genes including RLKs (Zhou et al. 2007, Qin et al. 2012, Jiang et al. 2013, Yang et al. 2013, Lee et al. 2014, Hu et al. 2018). All of these $R L K \mathrm{~s}$ are involved in wheat disease resistance, none of which were found to control photosynthesis. A large number of $R L K \mathrm{~s}$ are expected in wheat considering its large genome. However, only a few wheat $R L K$ s were characterized (Wang et al. 2015), which restricts wheat genetic improvement to a large extent. To offer potential target genes for wheat RUE improvement, the objective in this study was to explore the role of an uncharacterized RCLK gene, TaRLK1, in the regulation of photosynthesis in wheat by using the BSMV-VIGS system.

\section{Materials and methods}

Plant growth: A newly developed winter wheat advanced line Triticum aestivum L. cv. Xiaoyan 101 was used in this study. The seedling culture medium and growth conditions were performed as described previously ( $\mathrm{Li}$ et al. 2017, 2019; Liu et al. 2019). The germinated seeds were grown in a growth chamber (HP-1000GS, Wuhan Ruihua Instrument \& Equipment Co., Ltd., China). The growth conditions were set as follows: PPFD of $200 \mu \mathrm{mol} \mathrm{m}{ }^{-2} \mathrm{~s}^{-1}, 16-\mathrm{h}$ photoperiod, $23 / 18^{\circ} \mathrm{C}$ (light/dark), and relative humidity of $40-60 \%$. The culture medium was renewed every $3 \mathrm{~d}$. At the three-leaf stage (about $18 \mathrm{~d}$ after germination), the second leaves were used for inoculation.

RNA extraction and first-strand cDNA synthesis: The TRIzol Reagent (Thermo Fisher Scientific, USA) was 
used to isolate total RNA following the standard procedures. After assay of RNA quantity and quality with a spectrophotometer Nanodrop 2000 (Thermo Fisher Scientific, USA), $2 \mu \mathrm{g}$ of total RNA was used to synthesize the first-strand cDNA in $20-\mu \mathrm{L}$ reaction solution with a Goldenstar ${ }^{\mathrm{TM}}$ RT6 cDNA Synthesis Mix kit (TsingKe Biotech Co., Ltd., Beijing, China) according to the manufacture's instruction. Then, the first-strand cDNA was diluted to $80 \mu \mathrm{L}$ of the final volume with DNase-free water.

BSMV-VIGS assay of TaRKL1: A cDNA fragment of TaRKL1 was amplified from Xiaoyan 101 cDNA with the gene-specific primers (RKL1BF: 5'-GGCTAGCTGCTCCTGGAACTGATAACC-3' and RKL1BR: 5'-GGCTAGCTCTTCAAGCATTTACCTGCC-3') designed according to Chinese Spring reference gene TraesCS2A01G510300.1. The underlined letters indicate the Nhe I sites for $\gamma$ vector construction. Polymerase chain reaction (PCR) was conducted with the Applied Biosystems Veriti 96-Well Fast Thermal Cycler (Thermo Fisher Scientific, USA) in the $20-\mu \mathrm{L}$ reaction solution with a KOD Plus kit (TOYOBO, Japan). After the PCR products were purified with a TIANprep Mini Plasmid Kit (Tiangen Biotech Co., Ltd., Beijing, China), they were inserted into the pEASY-Blunt Cloning Vector (Tiangen Biotech Co., Ltd., Beijing, China) and transformed to the DH5 $\alpha$ competent E. coli cells. Subsequently, the plasmids were extracted and purified with a TIANgel Midi Purification Kit (Tiangen Biotech Co., Ltd., Beijing, China) and fragmented with Nhe I after the positive clones were screened and sequenced. Then, the target fragments were purified and inserted into the Nhe I digested $\gamma$ vector with $\mathrm{T}_{4}$ ligase (Promega, USA). The $\gamma$ :TaRKL1 vector was confirmed by sequencing. The empty $\gamma$ vector $\gamma: 00$ was taken as control.

After linearization of $\alpha, \gamma: T a R K L 1$, and $\gamma: 00$ vectors with Mlu I and $\beta$ vectors with Spe I, RNAs of $\alpha, \beta$, $\gamma:$ TaRKL1, and $\gamma: 00$ were in vitro transcribed in $50-\mu \mathrm{L}$ reaction solution with a RiboMAX ${ }^{T M}$ Large Scale $R N A$ Production System kit (Promega, USA). The transcribed RNAs were detected in $1.5 \%$ agar gel before they were used for inoculation according to Petty et al. (1989). Equal quantities of $\alpha, \beta$, and $\gamma$ RNAs were mixed before they were added in $200 \mu \mathrm{L}$ of GKP buffer consisting of $50 \mathrm{mM}$ glycine, $30 \mathrm{mM} \mathrm{K}_{2} \mathrm{HPO}_{4}, 1 \%$ (w/v) bentonite, and $1 \%(\mathrm{w} / \mathrm{v})$ celite in $\mathrm{pH} 9.2$. Finally, $10 \mu \mathrm{L}$ of the RNA mixture was inoculated onto wheat leaves with gloved fingers. Then, the inoculated plants were kept in darkness at $26-28^{\circ} \mathrm{C}$ for $48 \mathrm{~h}$ before they were transferred to the growth chamber.

Gene expression analysis: Quantitative PCR (qPCR) was performed to assay gene expression with the StepOnePlus Real-Time PCR Systems (Thermo Fisher Scientific, USA). It was performed following three-step PCR procedures in $10 \mu \mathrm{L}$ of the reaction solution consisting of $2 \mu \mathrm{L}$ of cDNA, $5 \mu \mathrm{L}$ of $2 \times$ PowerUp SYBR Green Master Mix (Thermo Fisher Scientific, USA), $0.2 \mu \mathrm{L}$ of $10 \mathrm{mM}$ gene-specific primers, and $2.6 \mu \mathrm{L}$ of DNase-free water. The TaActin was used as an internal reference gene as described by Uauy et al. (2006). Four replicates were carried out for each sample. The relative gene expression was calculated following the $2^{-\Delta \Delta \mathrm{Ct}}$ method (Schmittgen and Livak 2008). The sequences of qPCR primers used in this study were shown in Table 1S (supplement). The qPCR primers for genes encoding antioxidant enzymes, TaSAGs, TaPEPC, and $\operatorname{TarbcS}$ were described previously (Li et al. 2014, Liu et al. 2019). While the qPCR primers for the other genes were designed according to Chinese Spring reference genes with Primer Express (version 3.01). Gene expression assays were performed in the middle parts of the seventh leaves from the BSMV infected plants at $57 \mathrm{~d}$ post-inoculation (dpi).

The original relative expression data were logtransformed before the hierarchical clustering (HCL) analysis was conducted. It was performed with Pearson's correlation distance metric and average linkage clustering method in the software Multiple Array Viewer (version 4.9) (Saeed et al. 2003).

Gas-exchange measurement: The gas-exchange parameters including $\mathrm{CO}_{2}$ assimilation rate $\left(P_{\mathrm{N}}\right)$, stomatal conductance $\left(g_{\mathrm{s}}\right)$, transpiration rate $(E)$, and intercellular $\mathrm{CO}_{2}$ concentration $\left(C_{\mathrm{i}}\right)$ were determined with a portable photosynthetic system (LI-6400, LI-COR, USA). The middle parts of the leaves were measured and the measuring parameters in the leaf chamber were set as follows: the light intensity of $500 \mu \mathrm{mol}$ (photon) $\mathrm{m}^{-2} \mathrm{~s}^{-1}$, $400 \mu \mathrm{mol}\left(\mathrm{CO}_{2}\right) \mathrm{mol}^{-1}$, the temperature of $26^{\circ} \mathrm{C}$, the relative humidity of 55-60\%, and the airflow rate of $500 \mu \mathrm{mol} \mathrm{s}{ }^{-1}$. At $34 \mathrm{dpi}$, the fifth leaves were used for measurements. Usually, 6-8 plants were measured for each genotype and three reads were recorded for each plant.

Chlorophyll (Chl) $\boldsymbol{a}$ fluorescence measurement: Chl $a$ fluorescence was measured with a Handy-PEA fluorometer (Hansatech Instruments Ltd., UK). At 57 dpi, the seventh leaves were used for measurements. The middle parts of leaves were measured immediately after dark adaption for $30 \mathrm{~min}$. The saturated flashlight intensity was set at PPFD of 3,000 $\mu \mathrm{mol} \mathrm{m} \mathrm{m}^{-2} \mathrm{~s}^{-1}$ with 1 -s duration. The Chl $a$ fluorescence JIP-test parameters including maximum photochemical efficiency of PSII $\left(\mathrm{F}_{\mathrm{v}} / \mathrm{F}_{\mathrm{m}}\right)$, the probability that a trapped exciton moves an electron into the electron transport chain beyond $\mathrm{Q}_{\mathrm{A}^{-}}($at $\mathrm{t}=0)\left(\psi_{0}\right)$, the quantum yield of electron transport (at $\mathrm{t}=0)\left(\varphi_{\mathrm{Eo}}\right)$, performance index on absorption basis $\left(\mathrm{PI}_{\mathrm{ABS}}\right)$, electron transport flux per excited cross-section $\left(\mathrm{ET}_{0} / \mathrm{CS}\right)$, and dissipated energy flux per excited cross-section $\left(\mathrm{DI}_{0} / \mathrm{CS}\right)$ were computed and output with the software PEA Plus (version 1.10). These JIP-test parameters were computed according to Strasser et al. $(1995,2004)$.

Physiological and biochemical measurements: The content of total $\mathrm{Chl}[\mathrm{Chl}(a+b)], \mathrm{Chl} a, \mathrm{Chl} b$, and carotenoids (Car) were extracted and assayed as described by Arnon (1949) and Lichtenthaler and Wellburn (1983). About $0.05 \mathrm{~g}$ of leaf sample was extracted in $1 \mathrm{~mL}$ of $80 \%$ acetone 
in darkness at room temperature until it turned to white completely. Then, the extracts were spectrophotometrically measured at 470,645, 646, and $663 \mathrm{~nm}$ with a microplate reader (SpectraMax190, Molecular Devices, USA).

According to De la Fuente et al. (1995), the $\mathrm{O}_{2}{ }^{-}$content was determined by recording the decrease of absorbance at $530 \mathrm{~nm}$ per min with a microplate reader (SpectraMax190, Molecular Devices, USA). The $\mathrm{H}_{2} \mathrm{O}_{2}$ contents were assayed following Velikova et al. (2000) with small modifications. Leaf samples were extracted from $0.05 \mathrm{~g}$ in $2 \mathrm{~mL}$ of $0.1 \% \mathrm{TCA}$, followed by a reaction with potassium iodide. Then, the $\mathrm{H}_{2} \mathrm{O}_{2}$ content was calculated by recording the absorbance at $390 \mathrm{~nm}$ with a microplate reader (SpectraMax190, Molecular Devices, USA) according to a standard curve prepared with different concentrations of $\mathrm{H}_{2} \mathrm{O}_{2}$.

The content of malondialdehyde (MDA) and soluble sugar content was determined and computed according to Ledwożyw et al. (1986) and Zhao et al. (1994). About $0.05 \mathrm{~g}$ of leaves sample was homogenized in liquid nitrogen and extracted with $1.5 \mathrm{~mL}$ of $5 \%$ trichloroacetic acid (TCA) solution. After centrifugation at 12,000 rpm for $15 \mathrm{~min}$, the supernatant was transferred and mixed with an equal volume of $0.6 \%(\mathrm{w} / \mathrm{v})$ thiobarbituric acid dissolved with 5\% TCA. The mixture was incubated in boiling water for $15 \mathrm{~min}$, quickly cooled in an ice bath before it was spectrophotometrically measured at 450, 532, and $600 \mathrm{~nm}$ (SpectraMax190, Molecular Devices, USA).

The soluble proteins were extracted with the Total Protein Extraction Kit and quantified with the Protein Quantitation Kit (Applygen Technologies Inc., China) according to the manufacturer's instruction. The activity of Rubisco (EC 4.1.1.39) and antioxidant enzymes including superoxide dismutase (SOD, EC 1.15.1.1), catalase (CAT, EC 1.11.1.6), ascorbate peroxidase (APX, EC 1.11.1.11), and peroxidase (POD, EC 1.11.1.7) were assayed as described by Liu et al. (2019). Rubisco activity was computed through the decrease of absorbance at $340 \mathrm{~nm}$ wavelength in $5 \mathrm{~min}$. One unit of Rubisco activity was defined as to oxidize $1 \mathrm{nmol} \mathrm{NADH}$ per $1 \mathrm{~min}$ at $25^{\circ} \mathrm{C}$. Following García-Triana et al. (2010), the SOD activity was measured by recording the absorbance at $560 \mathrm{~nm}$. One unit of SOD activity was defined by the amount of enzyme inhibiting the nitroblue tetrazolium photoreduction by $50 \%$. Through recording the decrease of absorbance at $240 \mathrm{~nm}$ per min using the extinction coefficient of $0.043 \mathrm{mM}^{-1} \mathrm{~cm}^{-1}$, the CAT activity was measured according to Sima et al. (2011). The APX activity was assayed by recording the decrease of absorbance at $290 \mathrm{~nm}$ per min using the extinction coefficient of $2.8 \mathrm{mM}^{-1} \mathrm{~cm}^{-1}$ as described by Ullah et al. (2016). The POD activity was carried out by recording the increase of absorbance at $470 \mathrm{~nm}$ wavelength per min using the extinction coefficient of $26.6 \mathrm{mM}^{-1} \mathrm{~cm}^{-1}$ following Wang et al. (2014). All enzyme activities were calculated as unit $\mathrm{g}^{-1}(\mathrm{FM})$. All the wavelengths were measured with a microplate reader (SpectraMax190, Molecular Devices, USA).
Statistical analysis: Data were represented as means \pm SD. An independent $t$-test was performed by using SPSS statistical software (version 19.0, IBM). Data figures were carried out with the software SigmaPlot (version 10.0).

\section{Results}

Silencing of TaRKL1 in wheat reduced the photosynthetic rate: To explore the role of RLKs in the regulation of photosynthesis in wheat, an uncharacterized gene TaRKL1 (TraesCS2A01G510300.1) was silenced in wheat. Prediction of its deduced protein sequence showed that TaRKL1 has only one intracellular kinase domain without transmembrane or extracellular domains, indicating that it is the RLCK. The kinase domain of TaRKL1 exhibited the highest homology to the Arabidopsis RKL1 (At1g48480.1, $53.5 \%$ identity) and rice OsRLCK377 (Os03t0223000-02, $53.5 \%$ identity). A 191-bp TaRKL1 cDNA fragment spanning 677-868 bp downstream of the start codon corresponding to the kinase domain was used to construct an antisense BSMV $\gamma:$ TaRKL1 vector (BSMV:TaRKL1 for brief thereafter). The phenotypes of whole plants and leaves in the BSMV: $\gamma 00$ and BSMV:TaRKL1 infected plants were shown in Fig. $1 A, B$. No obvious difference was observed for the seedlings, roots, and leaves. Visible stripe virus infection symptoms were observed in the leaves of both the BSMV: $\gamma 00$ and BSMV:TaRKL1 plants, reflecting that BSMV infected sufficiently the plants. Consistently, no significant difference was detected for the plant height, maximum root length, tiller number, and fresh mass between the $B S M V: \gamma 00$ and BSMV:TaRKL1 plants grown under either low light or high light conditions at $20 \mathrm{dpi}$ (data not shown). qPCR assay of the seventh leaves at 57 dpi demonstrated that the expression level of TaRKL1 in leaves of the BSMV:TaRKL1 plants was reduced approximately to one-third of that in the $B S M V: \gamma 00$ plants, indicating that TaRKL1 was silenced efficiently (Fig. 1C). The gas-exchange parameters, such as $P_{\mathrm{N}}$ (Fig. $1 D$ ), $g_{\mathrm{s}}$ (Fig. $1 E$ ), and $E$ (Fig. $1 G$ ), in the fifth leaves of the BSMV:TaRKL1 plants at 34 dpi declined substantially compared with those of the BSMV: $\gamma 00$ plants. However, no significant reduction was observed for $C_{\mathrm{i}}$ between the $B S M V: \gamma 00$ and $B S M V: T a R K L 1$ plants (Fig. $1 F)$.

Silencing of TaRKL1 in wheat reduced PSII photochemical efficiency: The Chl $a$ fluorescence reflecting photosynthetic performance was analyzed to explore if the photochemical efficiency of PSII was influenced by silencing of TaRKL1 in wheat. As shown in Fig. 2, the values of $\mathrm{F}_{\mathrm{v}} / \mathrm{F}_{\mathrm{m}}$ (Fig. $\left.2 A\right), \Psi_{0}$ (Fig. $\left.2 B\right), \varphi_{\mathrm{Eo}}$ (Fig. $2 C$ ), $\mathrm{PI}_{\mathrm{ABS}}$ (Fig. $2 D$ ), and $\mathrm{ET}_{0} / \mathrm{CS}$ (Fig. $2 E$ ) in the seventh leaves of the $B S M V$ :TaRKL1 plants at 57 dpi were significantly lower than those of the $B S M V: \gamma 00$ plants, demonstrating that the maximum photochemical efficiency of PSII, probability that a trapped exciton moves an electron into the electron transport chain beyond $\mathrm{Q}_{\mathrm{A}^{-}}$, quantum yield of electron transport, and electron transport flux per excited cross- 


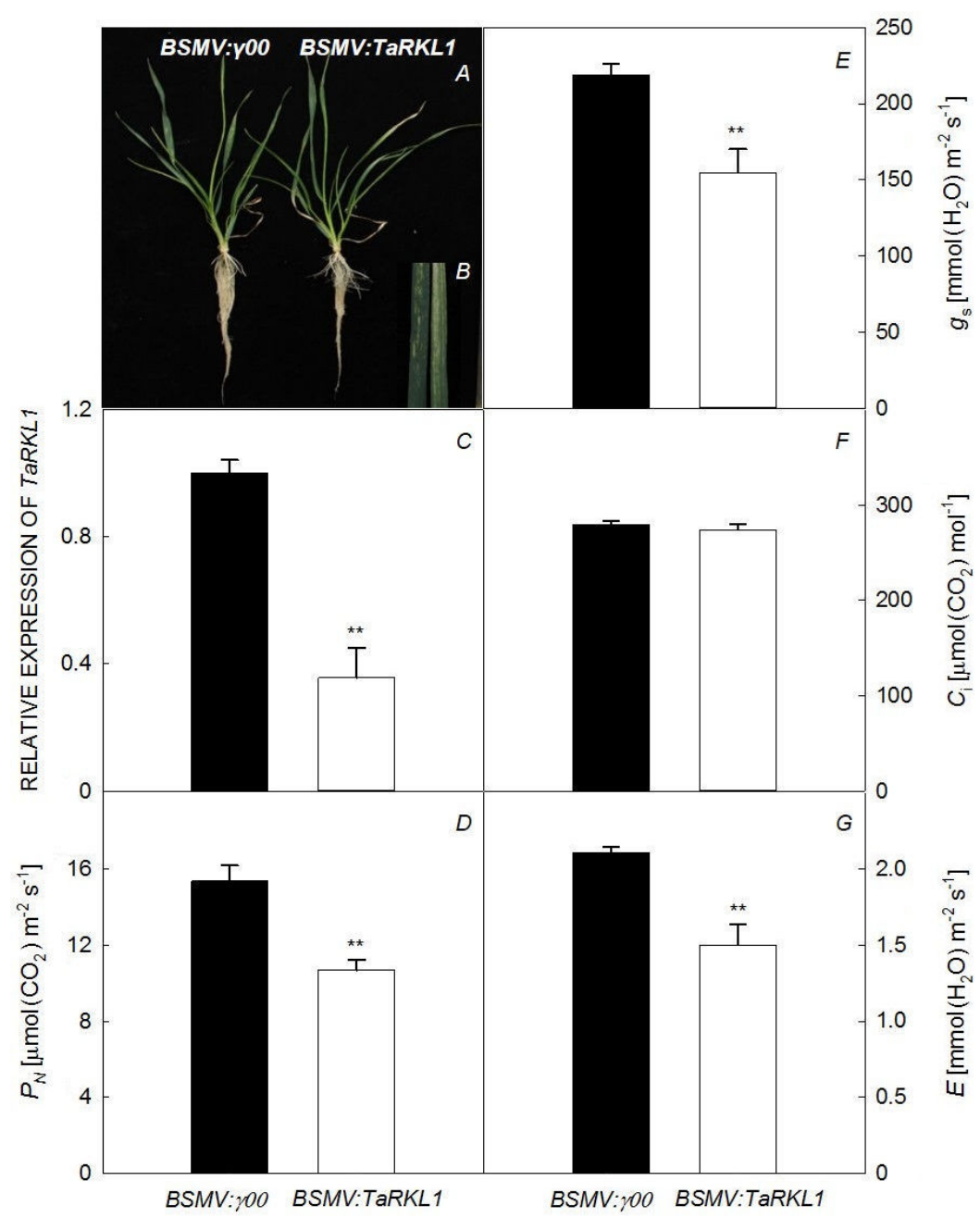

Fig. 1. The phenotypes, expression of TaRKL1, and gas-exchange parameters in the BSMV:y00 and BSMV:TaRKL1 plants. $(A)$ Typical structure of whole plants; $(B)$ leaf color; (C) relative expression of TaRKL1; $(D) \mathrm{CO}_{2}$ assimilation rate $\left(P_{\mathrm{N}}\right) ;(\mathrm{E})$ stomatal conductance $\left(g_{\mathrm{s}}\right) ;(F)$ intercellular $\mathrm{CO}_{2}$ concentration $\left(C_{\mathrm{i}}\right) ;(G)$ transpiration rate $(E)$. Data are represented as means $\pm \mathrm{SD} .{ }^{* *}$ denotes a significant difference at $P<0.01$. section were all reduced in the BSMV:TaRKL1 plants. Meanwhile, the value of $\mathrm{DI}_{0} / \mathrm{CS}$ enhanced significantly in the BSMV:TaRKL1 plants compared with the BSMV: $\gamma 00$ plants (Fig. $2 F$ ), indicating that the dissipated energy flux per excited cross-section was enhanced in the BSMV:TaRKL1 plants. The decline of photochemical efficiency of PSII seemed to be associated with the decrease of $P_{\mathrm{N}}$ in the BSMV:TaRKL1 plants.

Silencing of TaRKL1 in wheat reduced photosynthetic pigment contents: Photosynthetic pigments Chl and Car binding with $\mathrm{Chl} a / b$-binding proteins absorb and converse light energy, and thus drive photosynthesis. To uncover if the reduction of $P_{\mathrm{N}}$ in the $B S M V$ :TaRKL1 plants occurred due to the reduction of photosynthetic pigments, the contents of $\mathrm{Chl}$ and Car were assayed in the seventh leaves in the BSMV-infected plants at $57 \mathrm{dpi}$. As shown in Fig. 3 , the content of Chl $(a+b), \mathrm{Chl} a$, Chl $b$, and Car declined significantly in the BSMV:TaRKL1 plants compared with the $B S M V: \gamma 00$ plants. Besides, the ratio of $\mathrm{Chl}(a+b) / \mathrm{Car}$ also decreased significantly in the BSMV:TaRKL1 plants. However, the ratio of $\mathrm{Chl} a / b$ in the BSMV:TaRKL1 plants was significantly higher than that in the $B S M V: \gamma 00$ plants. Therefore, it seemed that the reduction of $\mathrm{Chl}$ and
Car may be associated with the reduction of $P_{\mathrm{N}}$ in the $B S M V: T a R K L 1$ plants. It appeared that TaRKL1 may play a role in the regulation of $\mathrm{Chl}$ and Car contents as well as Chl $a / b$ in wheat.

Silencing of TaRKL1 in wheat enhanced $\mathrm{H}_{2} \mathrm{O}_{2}$ accumulation: Further assays revealed that no significant difference was observed for the Rubisco activity between the BSMV:TaRKL1 and BSMV: $\gamma 00$ plants, although the soluble protein content declined significantly when TaRKL1 was silenced in wheat (Fig. 4A,B). Besides, no significant difference was also found for the $\mathrm{O}_{2}{ }^{--}$content (Fig. $4 C$ ). However, in comparison with the $B S M V: \gamma 00$ plants, the content of $\mathrm{H}_{2} \mathrm{O}_{2}$ and soluble sugar elevated significantly in the BSMV:TaRKL1 plants (Fig. $4 D-E$ ). On the contrary, the MDA content declined in the BSMV:TaRKL1 plants (Fig. $1 F$ ), suggesting that $\mathrm{H}_{2} \mathrm{O}_{2}$ enhancement did not result in lipid peroxidation of cellular membranes.

The activity of antioxidant enzymes was also determined to certify if repression of ROS-scavenging enzymes activity resulted in ROS enhancement in the BSMV:TaRKL1 plants. The SOD activity in the BSMV:TaRKL1 plants was not significantly different from that of the $B S M V: \gamma 00$ plants (Fig. 5A), which was consistent with the $\mathrm{O}_{2}{ }^{-}$content. Also, 


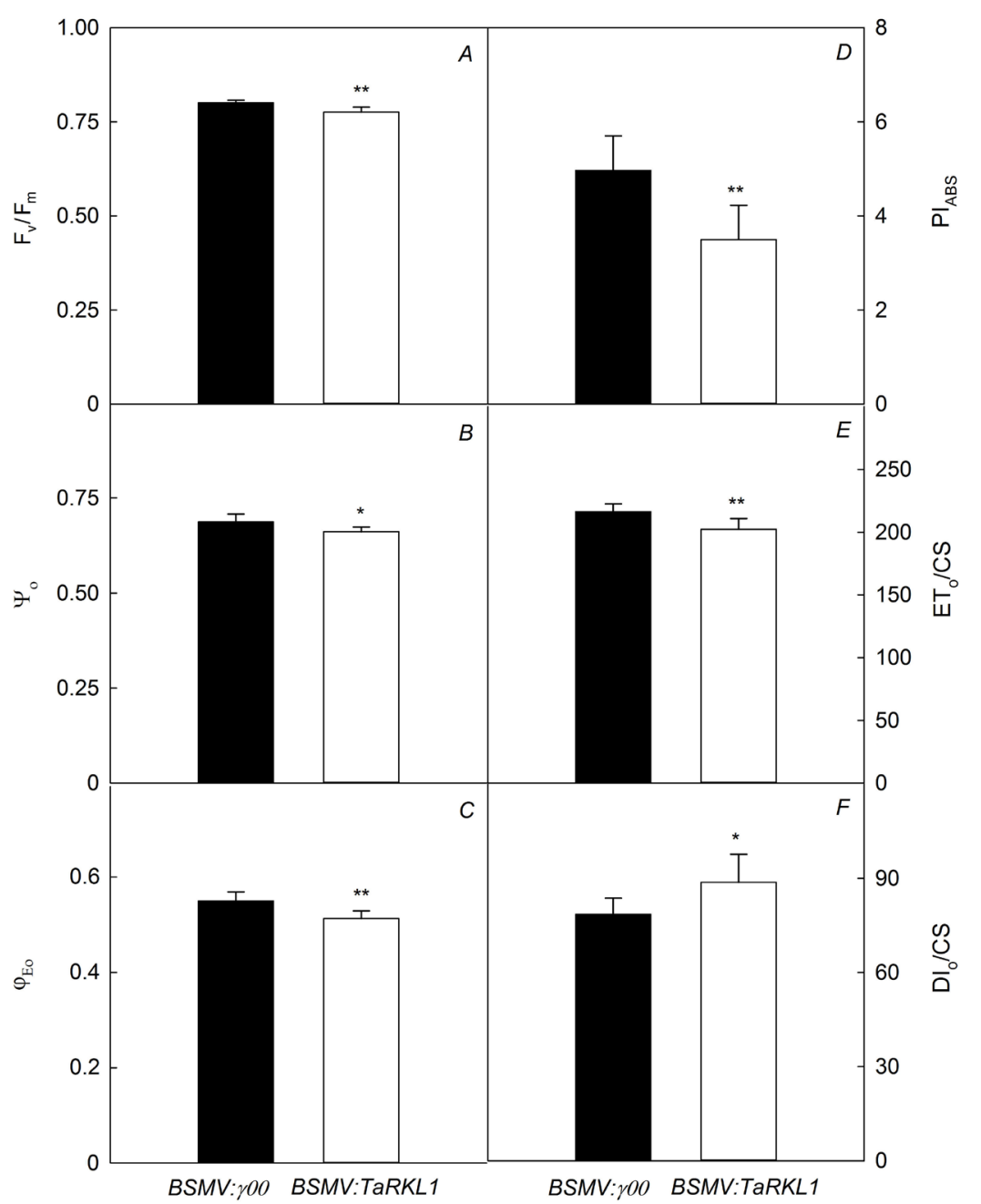

Fig. 2. The chlorophyll a fluorescence JIP-test parameters in the $B S M V: \gamma 00$ and $B S M V$ :TaRKL1 plants. (A) Maximum photochemical quantum efficiency of PSII $\left(\mathrm{F}_{\mathrm{v}} / \mathrm{F}_{\mathrm{m}}\right)$; $(B)$ probability that a trapped exciton moves an electron into the electron transport chain beyond $\mathrm{Q}_{\mathrm{A}^{-}}($at $\mathrm{t}=0)\left(\psi_{0}\right) ;(C)$ quantum yield of electron transport $($ at $\mathrm{t}=0)\left(\varphi_{\mathrm{Eo}}\right)$; $(D)$ performance index on absorption basis $\left(\mathrm{PI}_{\mathrm{ABS}}\right) ;(E)$ electron transport flux per crosssection $\left(\mathrm{ET}_{0} / \mathrm{CS}\right) ; \quad(F)$ dissipated energy flux per cross-section $\left(\mathrm{DI}_{0} / \mathrm{CS}\right)$. Data are represented as means $\pm \mathrm{SD} .{ }^{*}$ and ${ }^{* *}$ denote significant difference at $P<0.05$ and 0.01 , respectively. no significant difference was found for both the activity of CAT and POD between the BSMV:TaRKL1 and BSMV: 00 plants. However, the APX activity in the BSMV:TaRKL1 plants was reduced significantly compared with the $B S M V: \gamma 00$ plants, suggesting that $\mathrm{H}_{2} \mathrm{O}_{2}$ enhancement in the BSMV:TaRKL1 plants was largely ascribed to the reduction of the APX activity.

Silencing of TaRKL1 in wheat altered genes expression: To explore the roles of TaRKL1 in the regulation of photosynthesis, Chl biosynthesis, and ROS-scavenging enzymes at the mRNA level, the expression levels of a total of 32 genes involved in photosynthesis, Chl biosynthesis, antioxidant enzymes, ABA biosynthesis, and TaSAGs were assayed as described above. The HCL of these gene expression patterns was shown in Fig. 6. Of these, 21 genes expressed differentially and significantly between the BSMV:TaRKL1 and BSMV: 00 plants. For instance, TaSAG7 was significantly induced while TaSAG1, TaSAG4, TaSAG6, and TaSAG12 were downregulated in the BSMV:TaRKL1 plants compared with the control. Since more $S A G$ s were downregulated rather than induced in the BSMV:TaRKL1 plants, leaf senescence was not accelerated by the silencing of TaRKL1 in wheat. Consistent with the decline of $\mathrm{CO}_{2}$ assimilation rate, photochemical efficiency of PSII and the content of Chl and Car, TaPsbA encoding PSII reaction center D1 protein, TaPsbR encoding PSII $10 \mathrm{kD}$ polypeptide, TaPsaN encoding PSI reaction center subunit N, TaPEPC encoding phosphoenolpyruvate carboxylase, TarbcS encoding Rubisco small subunit, TaCHLH encoding Mg-chelatase subunit $\mathrm{H}$, and TaDVR encoding 3,8-divinyl protochlorophyllide $a$ 8-vinyl reductase were all significantly suppressed in the $B S M V: T a R K L 1$ plants. Also, expression levels of TaFeSOD, TaMnSOD, TaCu/ZnSOD, TaAPX, and TaMDAR encoding monodehydroascorbate reductase also declined significantly in the BSMV:TaRKL1 plants, which were consistent with $\mathrm{H}_{2} \mathrm{O}_{2}$ enhancement in the $B S M V$ :TaRKL1 plants. Additionally, the expression levels of genes involving ABA biosynthesis, for instance, $T a A B A 1$ encoding zeaxanthin epoxidase, TaABA4 encoding protein ABA DEFICIENT 4, TaNCED4 encoding 9-cis-epoxycarotenoid dioxygenase, and TaABA2 encoding xanthoxin dehydrogenase were also significantly downregulated in the BSMV:TaRKL1 plants, suggesting that ABA biosynthesis may be repressed at the transcription level in the BSMV:TaRKL1 plants. 


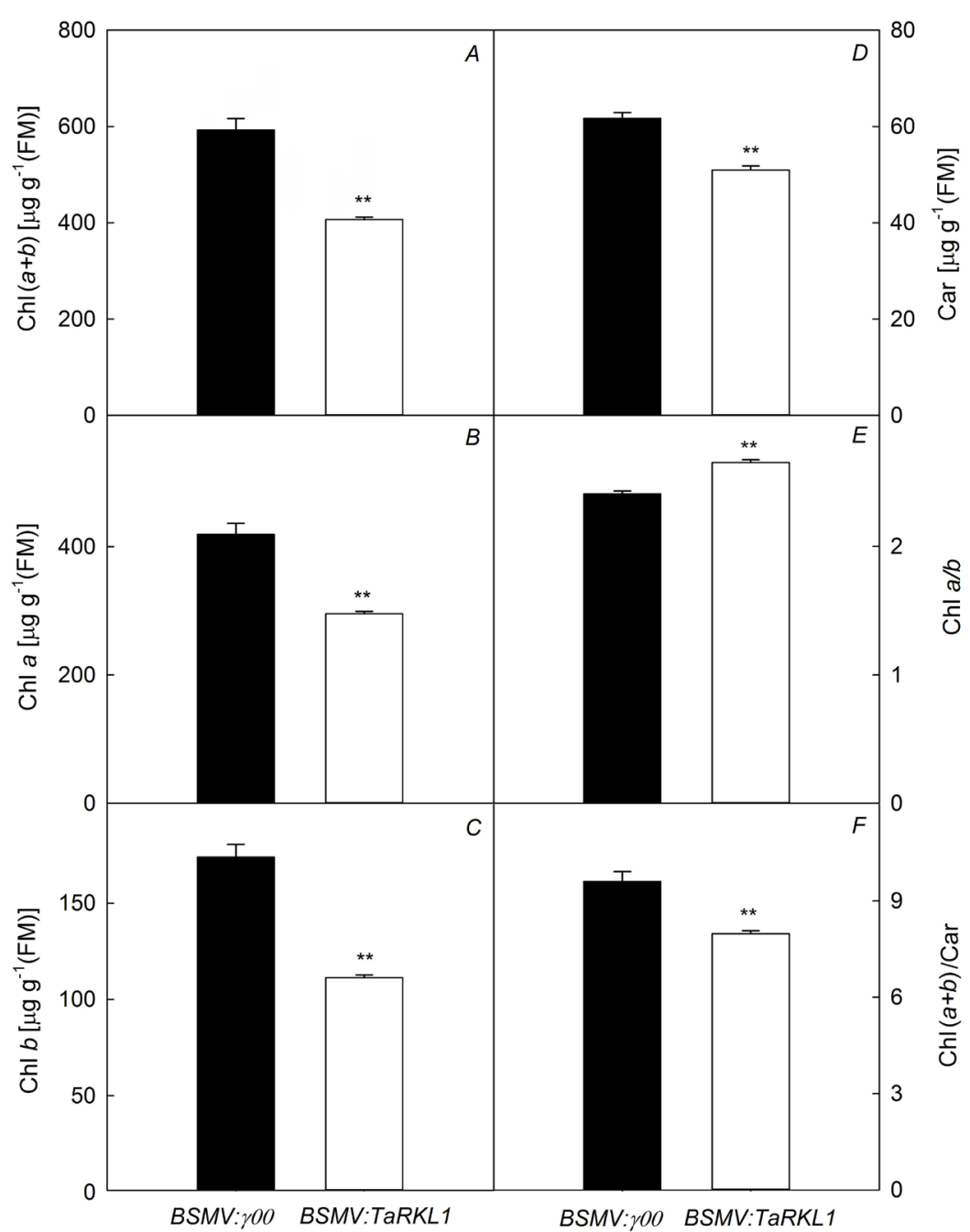

Fig. 3. The content of photosynthetic pigments in the BSMV: $\gamma 00$ and BSMV:TaRKL1 plants. (A) Total chlorophyll content [Chl $(a+b)]$; (B) chlorophyll $a$ content $(\mathrm{Chl} a)$; (C) chlorophyll $b$ content $(\mathrm{Chl} b)$; $(D)$ carotenoids content (Car); (E) the ratios of Chl $a$ to $\mathrm{Chl} b$ $(\mathrm{Chl} a / b) ;(F)$ the ratios of $\mathrm{Chl}(a+b)$ to $\mathrm{Car}$ [Chl $(a+b) / \mathrm{Car}]$. Data are represented as means \pm SD. ${ }^{* *}$ denotes significant difference at $P<0.01$.

\section{Discussion}

In plants, $R L K$ s belong to one of the largest protein-coding gene families and play crucial and diverse roles in the regulation of plant development and response to stress through RLKs signaling (Liang and Zhou 2018). Some of the $R L K$ s characterized in the model plants like Arabidopsis and rice can be useful for the genetic improvement of cereal crops. Although some RLKs are found to play roles in the regulation of stomatal development and closure (Nadeau and Sack 2002, Masle et al. 2005, Shpak et al. 2005, Keerthisinghe et al. 2015, Shang et al. 2016), transpiration efficiency (Masle et al. 2005), cell death (Zhang et al. 2019), and leaf senescence (Shin et al. 2020), no direct evidence was found for RLKs to regulate photosynthesis. Identification of $R L K \mathrm{~s}$ regulating photosynthesis may favor RUE improvement of cereal crops. For wheat, an important staple food source for human beings, only a few wheat $R L K \mathrm{~s}$ have been identified to regulate resistance to diseases (Wang et al. 2015), which are surely not sufficient for genetic improvement, especially for RUE improvement in wheat. Therefore, it is necessary to characterize $R L K \mathrm{~s}$ regulating photosynthesis for wheat RUE improvement.
In this study, for the first time, an uncharacterized RCLK gene, TaRLK1, was found to regulate photosynthesis in wheat. When TaRLK1 was silenced in wheat, the $\mathrm{CO}_{2}$ assimilation rate, stomatal conductance, and transpiration rate declined significantly (Fig. 1). Accompanying with the reduction of stomatal conductance, the transpiration rate was consistently reduced in the $B S M V$ :TaRKL1 plants compared with the control. However, the reduction of $g_{\mathrm{s}}$ appears to be unrelated to the decline of $P_{\mathrm{N}}$ because no significant difference was observed for $C_{\mathrm{i}}$ between the BSMV:TaRKL1 and BSMV: $\gamma 00$ plants. The measurement of Chl $a$ fluorescence (JIP-test) parameters showed that $\mathrm{F}_{\mathrm{v}} / \mathrm{F}_{\mathrm{m}}$, $\mathrm{PI}_{\mathrm{ABS}}, \psi_{0}, \varphi_{\mathrm{E} o}$, and $\mathrm{ET}_{0} / \mathrm{CS}$ declined while $\mathrm{DI}_{0} / \mathrm{CS}$ increased significantly in the BSMV:TaRKL1 plants compared with the $B S M V: \gamma 00$ plants (Fig. 2), demonstrating that linear electron transport rate was inhibited while heat dissipated energy flux was enhanced in the BSMV:TaRKL1 plants. It can be deduced that the inhibition of the photochemical efficiency of PSII contributed to the decline of $P_{\mathrm{N}}$ in the BSMV:TaRKL1 plants.

Chl and Car are responsible for the absorption and conversion of light energy and thus promote photochemical processes (Green and Durnford 1996). 

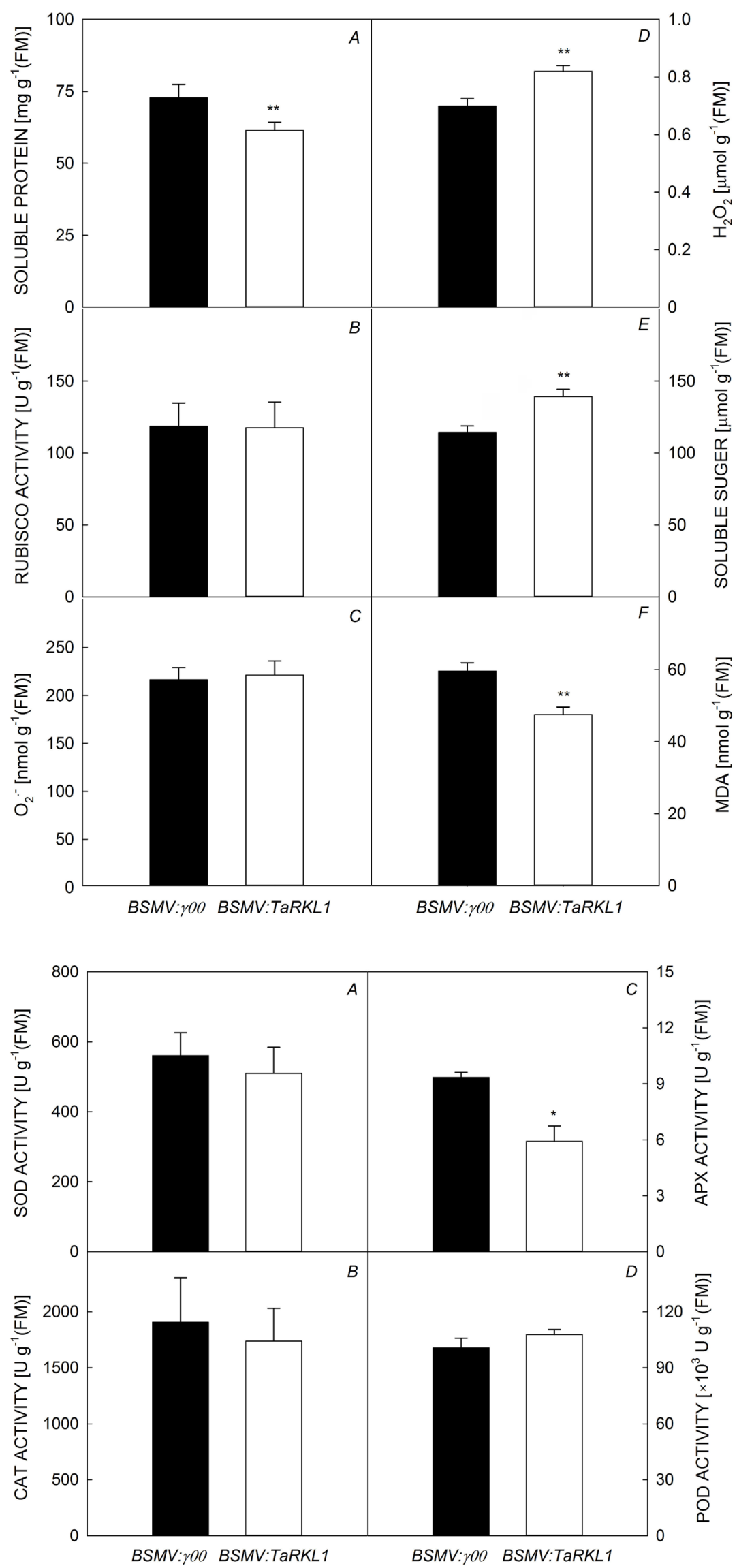

Fig. 4. The content of soluble protein $(A)$, $\mathrm{O}_{2}^{-}(C), \mathrm{H}_{2} \mathrm{O}_{2}(D)$, soluble sugar content $(E)$, and MDA $(F)$ as well as the Rubisco activity $(B)$ in the BSMV: $\gamma 00$ and BSMV:TaRKL1 plants. Data are represented as means $\pm \mathrm{SD}$. ${ }^{* *}$ denotes a significant difference at $P<0.01$.

Fig. 5. The activity of superoxide dismutase (SOD) $(A)$, catalase $(\mathrm{CAT})(B)$, ascorbate peroxidase (APX) $(C)$, and peroxidase (POD) $(D)$ in the $B S M V: \gamma 00$ and $B S M V: T a R K L 1$ plants. Data are represented as means $\pm \mathrm{SD} .{ }^{*}$ denotes significant difference at $P<0.05$. 


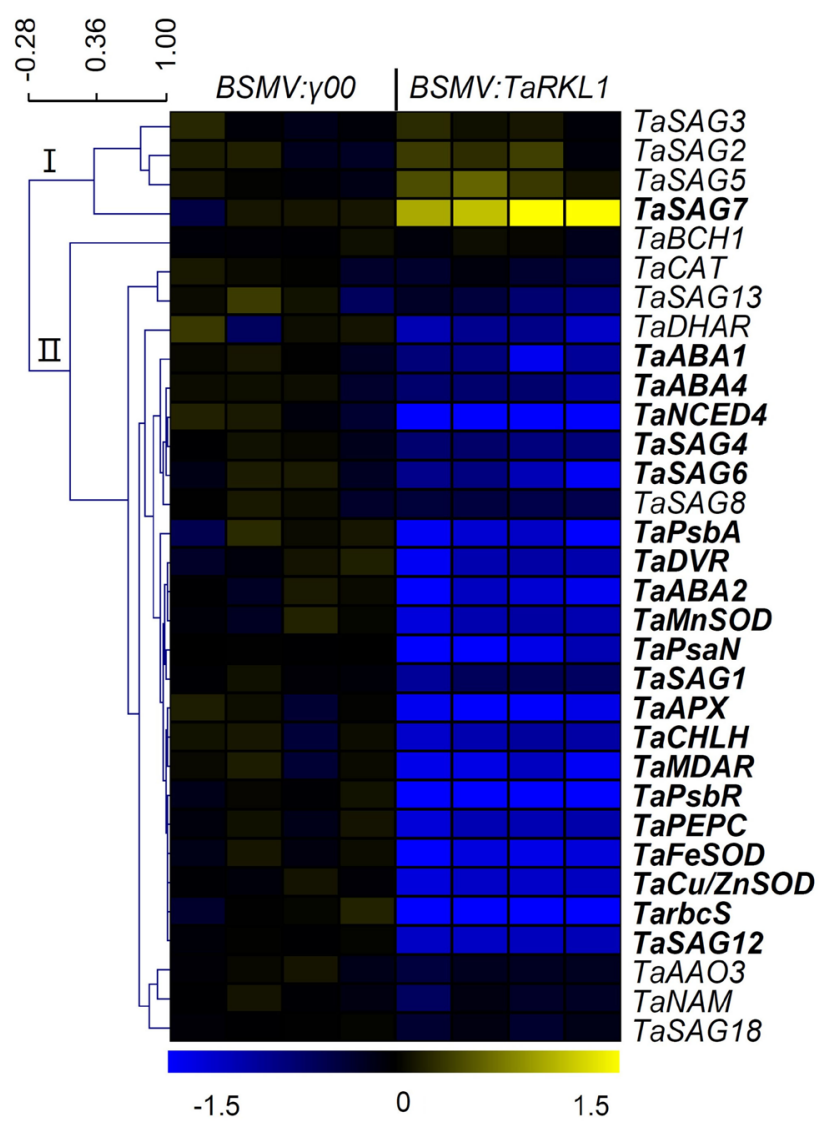

Fig. 6. Hierarchical clustering of expression of genes involving in photosynthesis, antioxidant enzymes, abscisic acid biosynthesis, and senescence in the BSMV: $\gamma 00$ and BSMV:TaRKL1 plants. The significantly different genes at $P<0.01$ were shown in bold.

The assay of photosynthetic pigments demonstrated that the content of Chl $(a+b), \mathrm{Chl} a$, Chl $b$, and Car were all consistently reduced in the BSMV:TaRKL1 plants (Fig. 3), suggesting that silencing of TaRKL1 in wheat declines the accumulation of photosynthetic pigments. Further gene expression analysis demonstrated that the two $\mathrm{Chl}$ biosynthesis genes, TaCHLH and TaDVR, were both repressed in the $B S M V$ :TaRKL1 plants, indicating that $\mathrm{Chl}$ biosynthesis may be repressed in the BSMV:TaRKL1 plants. Additionally, the expression levels of TaPsbA encoding PSII reaction center D1 protein, TaPsbR encoding PSII 10 kD polypeptide, and TaPsaN encoding PSI reaction center subunit $\mathrm{N}$ also declined in the BSMV:TaRKL1 plants, suggesting that the transcription of genes involved in both PSII and PSI reaction centers was suppressed. The lower content of Chl and Car might represent less $\mathrm{Chl} a / b$-binding proteins in light-harvesting complexes and reaction centers in the photosynthetic membranes, and thus it played a role in the reduction of $P_{\mathrm{N}}$ and photochemical efficiency in the $B S M V$ :TaRKL1 plants. Also, the $\mathrm{Chl} a / b$-binding protein is found to be involved in the responses of stomata to ABA guard cell signaling by modulating ROS homeostasis (Xu et al. 2012). The ratio of $\mathrm{Chl} a / b$ is related to the ratio of PSII core complex to the light-harvesting Chl $a / b$-binding protein complexes of PSII (LHCII) (Terashima and Hikosaka 1995). When TaRKL1 was silenced in wheat, the $\mathrm{Chl} a / b$ ratio enhanced significantly, indicating that the reduction magnitude of $\mathrm{Chl} b$ is pronounced relative to $\mathrm{Chl}$ $a$ in the BSMV:TaRKL1 plants. Hence, it can be deduced from $\mathrm{Chl} a / b$ ratio that LHCII complexes may decline in the BSMV:TaRKL1 plants.

Recent studies demonstrated that RLKs involved in cell death and leaf senescence (Zhang et al. 2019, Shin et al. 2020). To understand if the decline of $\mathrm{Chl}$ and Car in the BSMV:TaRKL1 plants was associated with leaf senescence, the expression of a set of 12 wheat $S A G$ s was analyzed in this work. The expression of five TaSAGs differed significantly between the BSMV:TaRKL1 and $B S M V: \gamma 00$ plants, only one of which (TaSAG7) was induced, while the other four (TaSAG1, TaSAG4, TaSAG6, and TaSAG12) were inhibited in the BSMV:TaRKL1 plants, demonstrating that no precocious leaf senescence occurred in the BSMV:TaRKL1 plants. Hence, TaRKL1 appeared to play a marginal role in the regulation of leaf senescence in wheat, although it may affect the content of Chl and Car.

Although the soluble protein content in the $B S M V$ : TaRKL1 plants declined, no significant difference was observed for the Rubisco activity between the $B S M V: T a R K L 1$ and BSMV: $\gamma 00$ plants. However, at the mRNA level, the transcripts of TarbcS, as well as TaPEPC were significantly lower in the BSMV:TaRKL1 plants compared to those in the control, indicating that TaRKL1 may involve in the transcription regulation of Rubisco small subunits but have marginal effects on Rubisco activity. Further measurements showed that no significant difference was found for $\mathrm{O}_{2}^{-}$content between the BSMV:TaRKL1 and BSMV: $\gamma 00$ plants. However, the $\mathrm{H}_{2} \mathrm{O}_{2}$ content in the BSMV:TaRKL1 plants was significantly higher than that in the $B S M V: \gamma 00$ plants, which was consistent with Ouyang et al. (2010). Investigation of the activity of ROS-scavenging enzymes showed that no significant difference was observed for SOD, CAT, and POD between the BSMV:TaRKL1 and BSMV: $\gamma 00$ plants. However, the APX activity in the BSMV:TaRKL1 was significantly lower than that in the $B S M V: \gamma 00$ plants, which should contribute to the higher $\mathrm{H}_{2} \mathrm{O}_{2}$ accumulation in the BSMV:TaRKL1 plants. Expression of seven genes encoding antioxidant enzymes showed that TaFeSOD, TaMnSOD, $T a C u / Z n S O D, T a A P X$, and TaMDAR were downregulated consistently and significantly in the BSMV:TaRKL1 plants. Although the SOD activity changed negligibly, the three SOD genes, TaFeSOD, TaMnSOD, and TaCu/ZnSOD, were all repressed in the BSMV:TaRKL1 plants. The inhibition of $\operatorname{TaAPX}$ was consistent with the repression of APX activity in the BSMV:TaRKL1 plants, suggesting that TaRKL1 may play a role in the regulation of $\mathrm{H}_{2} \mathrm{O}_{2}$ homeostasis through APX modulation. TaMDAR encodes monodehydroascorbate reductase (MDAR), an important enzyme of the ascorbate-glutathione cycle. Both APX and MDAR involve in $\mathrm{H}_{2} \mathrm{O}_{2}$ removal via ascorbic acid (AsA). The downregulation of TaMDAR in the BSMV:TaRKL1 plants indicates that AsA may also involve in the TaRLK1 signaling process. Although enhanced $\mathrm{H}_{2} \mathrm{O}_{2}$ accumulation was observed in the BSMV:TaRKL1 plants, the MDA 
content was lower rather than higher in the BSMV:TaRKL1 plants. It appeared that $\mathrm{H}_{2} \mathrm{O}_{2}$ enhancement did not result in lipid peroxidation of the cellular membrane, which was consistent with the downregulation of the four TaSAGs. It is more likely that $\mathrm{H}_{2} \mathrm{O}_{2}$ enhancement may act as ROS signal interacting with TaRKL1 signaling.

Evidence demonstrated that $\mathrm{H}_{2} \mathrm{O}_{2}$ acts as signal molecules in ABA-induced stomatal closure (Song et al. 2014). A few RLKs work upstream of ROS signaling and involve in ABA-induced stomatal closure. In this study, TaRKL1 seemed to control negatively $\mathrm{H}_{2} \mathrm{O}_{2}$ production in wheat. Expression of genes involved in ABA biosynthesis showed that four ABA biosynthesis genes, TaABA1, $T a A B A 4$, TaNCED4, TaABA2, were downregulated in the $B S M V: T a R K L 1$ plants. However, no significant differences were found for the expression of $\mathrm{TaBCH}$ and $\mathrm{TaAAO} 3$ between $B S M V: T a R K L 1$ and $B S M V: \gamma 00$ plants. AAO catalyzes the last step oxidation of abscisic aldehyde to produce $\mathrm{ABA}$ and results in simultaneous elevation of ABA and ROS contents (Zarepour et al. 2012). The changes of ABA contents were not only regulated by the change of gene expression, but also by enzymatic reaction. Besides, it is also not possible that $\mathrm{H}_{2} \mathrm{O}_{2}$ enhancement in the BSMV:TaRKL1 plants was due to the enhancement of the ABA content.

The TaRKL1 is an uncharacterized gene encoding an RCLK in wheat. Its kinase domain shows the highest homology to Arabidopsis RKL1 and rice OsRLCK377. In Arabidopsis, RKL1 shows a 75\% amino acid sequence identity to RLK902 (Tarutani et al. 2004). RLK902 was strongly expressed in the root tips, lateral root primordia, stipules, and floral organ abscission zones, while RKL1 was dominantly expressed in the stomata cells, hydathodes, and trichomes of young rosette leaves, and floral organ abscission zones. Neither the rlk902 nor rkllmutants nor the rlk902/rkl1 double mutants showed any significant phenotypes under normal growth conditions (Tarutani et al. 2004). However, further evidence showed that the rlk902 mutant showed both reduced root growth and resistance to downy mildew in a recessive manner (ten Hove et al. 2011). A very recent study showed that RLK902 was associated with and phosphorylated BRASSINOSTEROID SIGNALING KINASE1 (BSK1) as well as a key phosphorylation site (Ser-230) to regulate plant immunity signals (Zhao et al. 2019). It seemed that TaRKL1 plays a role in the regulation of photosynthesis unlike RKL1 and RKL902 in Arabidopsis. Further work is needed to understand the biochemical and molecular mechanism of TaRKL1 in the regulation of photosynthesis. Also, an allelic variation of TaRKL1 in wheat associated with improved RUE will offer an opportunity for wheat genetic improvement.

Conclusion: When TaRKL1 was silenced in wheat, the $\mathrm{CO}_{2}$ assimilation rate, stomatal conductance, transpiration rate, photochemical efficiency of PSII, the content of chlorophylls and carotenoids, APX activity, and expression levels of genes involved in photosynthesis, antioxidant enzymes, and ABA biosynthesis all declined significantly, while $\mathrm{H}_{2} \mathrm{O}_{2}$ accumulation, dissipated energy flux, and soluble sugar content were elevated significantly in the BSMV:TaRKL1 plants. The $\mathrm{H}_{2} \mathrm{O}_{2}$ accumulation did not result in lipid peroxidation of the cellular membrane and leaf senescence as the MDA content and most of the TaSAGs decreased in the BSMV:TaRKL1 plants. Hence, it appeared that TaRLK1 signaling interacts with the $\mathrm{H}_{2} \mathrm{O}_{2}$ signal in the regulation of photosynthesis in wheat.

\section{References}

Arnon D.I.: Copper enzymes in isolated chloroplasts. Polyphenoloxidase in Beta vulgaris. - Plant Physiol. 24: 1-15, 1949.

Asada K.: The water-water cycle in chloroplasts: Scavenging of active oxygens and dissipation of excess photons. - Annu. Rev. Plant Phys. 50: 601-639, 1999.

De la Fuente M., Hernanz A., Collazos M.E. et al.: Effects of physical exercise and aging on ascorbic acid and superoxide anion levels in peritoneal macrophages from mice and guinea pigs. - J. Comp. Physiol. B 165: 315-319, 1995.

Foyer C.H., Noctor G.: Redox sensing and signaling associated with reactive oxygen in chloroplasts, peroxisomes and mitochondria. - Physiol. Plantarum 119: 355-364, 2003.

García-Triana A., Zenteno-Savín T., Peregrino-Uriarte A.B., Yepiz-Plascencia G.: Reoxygenation and cytosolic manganese superoxide dismutase ( $c M n S O D)$ silencing in Litopenaeus vannamei: Effects on $c M n S O D$ transcripts, superoxide dismutase activity and superoxide anion production capacity. - Dev. Comp. Immunol. 34: 1230-1235, 2010.

Green B.R., Durnford D.G.: The chlorophyll-carotenoid proteins of oxygenic photosynthesis. - Annu. Rev. Plant Phys. 47: 685-714, 1996.

Hein I., Barciszewska-Pacak M., Hrubikova K. et al.: Virusinduced gene silencing-based functional characterization of genes associated with powdery mildew resistance in barley. Plant Physiol. 138: 2155-2164, 2005.

Horton P.: Prospects for crop improvement through the genetic manipulation of photosynthesis: morphological and biochemical aspects of light capture. - J. Exp. Bot. 51: 475$485,2000$.

Hu P., Liu J., Xu J. et al.: A malectin-like/leucine-rich repeat receptor protein kinase gene, $R L K-V$, regulates powdery mildew resistance in wheat. - Mol. Plant Pathol. 19: 25612574, 2018.

Huang L.Z., Yasir T.A., Phillips A.L., Hu Y.G.: Isolation and characterization of ERECTA genes and their expression patterns in common wheat (Triticum aestivum L.). - Aust. J. Crop. Sci. 7: 381-390, 2013.

Iwai S., Ogata S., Yamada N. et al.: Guard cell photosynthesis is crucial in abscisic acid-induced stomatal closure. - Plant Direct 3: e00137, 2019.

Jiang Z.N., Ge S., Xing L.P. et al.: RLP1.1, a novel wheat receptor-like protein gene, is involved in the defence response against Puccinia striiformis f. sp. tritici. - J. Exp. Bot. 64: 3735-3746, 2013.

Keerthisinghe S., Nadeau J.A., Lucas J.R. et al.: The Arabidopsis leucine-rich repeat receptor-like kinase MUSTACHES enforces stomatal bilateral symmetry in Arabidopsis. - Plant J. 81: 684-694, 2015.

Kimura S., Waszczak C., Hunter K., Wrzaczek M.: Bound by fate: The role of reactive oxygen species in receptor-like kinase signaling. - Plant Cell 29: 638-654, 2017.

Ledwożyw A., Michalak J., Stepień A., Kạdziołka A.: The relationship between plasma triglycerides, cholesterol, total lipids and lipid-peroxidation products during human 
atherosclerosis. - Clin. Chim. Acta 155: 275-283, 1986.

Lee W.S., Rudd J.J., Hammond-Kosack K.E., Kanyuka K.: Mycosphaerella graminicola LysM effector-mediated stealth pathogenesis subverts recognition through both CERK1 and CEBiP homologues in wheat. - Mol. Plant Microbe In. 27: 236-243, 2014.

Li H., Wang G., Liu S. et al.: Comparative changes in the antioxidant system in the flag leaf of early and normally senescing near-isogenic lines of wheat (Triticum aestivum L.). - Plant Cell Rep. 33: 1109-1120, 2014.

Li H., Zheng Q., Zhang J. et al.: The analysis of determining factors and evaluation of tolerance to photoinhibition in wheat (Triticum aestivum L.). - Photosynthetica 55: 69-76, 2017.

Li W.C., Liu Y.N., Liu M.M. et al.: Sugar accumulation is associated with leaf senescence induced by long-term high light in wheat. - Plant Sci. 287: 110169, 2019.

Liang X., Zhou J.M.: Receptor-like cytoplasmic kinases: Central players in plant receptor kinase-mediated signaling. - Annu. Rev. Plant Biol. 69: 267-299, 2018.

Lichtenthaler H.K., Wellburn A.R.: Determinations of total carotenoids and chlorophylls $a$ and $b$ of leaf extracts in different solvents. - Biochem. Soc. T. 11: 591-592, 1983.

Liu Y.N., Xu Q.Z., Li W.C. et al.: Long-term high light stress induces leaf senescence in wheat (Triticum aestivum L.). Photosynthetica 57: 830-840, 2019.

Masle J., Gilmore S.R., Farquhar G.D.: The ERECTA gene regulates plant transpiration efficiency in Arabidopsis. Nature 436: 866-870, 2005.

Nadeau J.A., Sack F.D.: Control of stomatal distribution on the Arabidopsis leaf surface. - Science 296: 1697-1700, 2002.

Ouyang S.Q., Liu Y.F., Liu P. et al.: Receptor-like kinase OsSIK1 improves drought and salt stress tolerance in rice (Oryza sativa) plants. - Plant J. 62: 316-329, 2010.

Petty I.T.D., Hunter B.G., Wei N., Jackson A.O.: Infectious barley stripe mosaic virus RNA transcribed in vitro from fulllength genomic cDNA clones. - Virology 171: 342-349, 1989.

Qin B., Chen T., Cao A. et al.: Cloning of a conserved receptorlike protein kinase gene and its use as a functional marker for homoeologous group-2 chromosomes of the Triticeae species. - PLoS ONE 7: e49718, 2012.

Richards R.A.: Selectable traits to increase crop photosynthesis and yield of grain crops. - J. Exp. Bot. 51: 447-458, 2000.

Saeed A.I., Sharov V., White J. et al.: TM4: a free, open-source system for microarray data management and analysis. Biotechniques 34: 374-378, 2003.

Schmittgen T.D., Livak K.J.: Analyzing real-time PCR data by the comparative CT method. - Nat. Protoc. 3: 1101-1108, 2008.

Scofield S.R., Huang L., Brandt A.S., Gill B.S.: Development of a virus-induced gene-silencing system for hexaploid wheat and its use in functional analysis of the $L r 21$-mediated leaf rust resistance pathway. - Plant Physiol. 138: 2165-2173, 2005.

Shang Y., Dai C., Lee M.M. et al.: BRI1-associated receptor kinase 1 regulates guard cell ABA signaling mediated by OPEN STOMATA 1 in Arabidopsis. - Mol. Plant 9: 447-460, 2016.

Shin N.H., Trang D.T., Hong W.J. et al.: Rice senescence-induced receptor-like kinase $(O S S R L K)$ is involved in phytohormonemediated chlorophyll degradation. - Int. J. Mol. Sci. 21: 26, 2020.

Shiu S.H., Bleecker A.B.: Plant receptor-like kinase gene family: diversity, function, and signaling. - Sci. STKE 2001: re22, 2001.

Shiu S.H., Karlowski W.M., Pan R. et al.: Comparative analysis of the receptor-like kinase family in Arabidopsis and rice. -
Plant Cell 16: 1220-1234, 2004.

Shpak E.D., McAbee J.M., Pillitteri L.J., Torii K.U.: Stomatal patterning and differentiation by synergistic interactions of receptor kinases. - Science 309: 290-293, 2005.

Shumayla, Sharma S., Kumar R. et al.: Genomic dissection and expression profiling revealed functional divergence in Triticum aestivum leucine rich repeat receptor like kinases (TaLRRKs). - Front. Plant Sci. 7: 1374, 2016.

Sima Y.H., Yao J.M., Hou Y.S. et al.: Variations of hydrogen peroxide and catalase expression in Bombyx eggs during diapause initiation and termination. - Arch. Insect Biochem. 77: 72-80, 2011

Song Y., Miao Y., Song C.P.: Behind the scenes: the roles of reactive oxygen species in guard cells. - New Phytol. 201: 1121-1140, 2014.

Strasser R.J., Srivastava A., Govindjee: Polyphasic chlorophyll $a$ fluorescence transient in plants and cyanobacteria. Photochem. Photobiol. 61: 32-42, 1995.

Strasser R.J., Tsimilli-Michael M., Srivastava A.: Analysis of the chlorophyll $a$ fluorescence transient. - In: Papageorgiou G.C., Govindjee (ed.): Chlorophyll $a$ Fluorescence: A Signature of Photosynthesis. Advances in Photosynthesis and Respiration. Pp. 321-362. Springer, Dordrecht 2004.

Tarutani Y., Morimoto T., Sasaki A. et al.: Molecular characterization of two highly homologous receptor-like kinase genes, RLK902 and RKL1, in Arabidopsis thaliana. - Biosci. Biotech. Bioch. 68: 1935-1941, 2004.

ten Hove C.A., de Jong M., Lapin D. et al.: Trans-repression of gene activity upstream of T-DNA tagged RLK902 links Arabidopsis root growth inhibition and downy mildew resistance. - PLoS ONE 6: e19028, 2011.

Terashima I., Hikosaka K.: Comparative ecophysiology of leaf and canopy photosynthesis. - Plant Cell Environ. 18: 1111$1128,1995$.

Uauy C., Distelfeld A., Fahima T. et al.: A NAC gene regulating senescence improves grain protein, zinc, and iron content in wheat. - Science 314: 1298-1301, 2006.

Ullah S., Kolo Z., Egbichi I. et al.: Nitric oxide influences glycine betaine content and ascorbate peroxidase activity in maize.S. Afr. J. Bot. 105: 218-225, 2016.

Velikova V., Yordanov I., Edreva A.: Oxidative stress and some antioxidant systems in acid rain-treated bean plants. Protective role of exogenous polyamines. - Plant Sci. 151: 59-66, 2000.

Wang H.F., Li X., Dong L.L. et al.: [Progress and prospects in the research on wheat receptor-like kinases and derivative proteins.] - Chin. Bull. Bot. 50: 255-262, 2015. [In Chinese with English abstract] doi: 10.3724/SP.J.1259.2015.00255.

Wang L., Wang Y.F., Wang X.Y. et al.: Regulation of POD activity by pelargonidin during vegetative growth in radish (Raphanus sativus L.). - Sci. Hortic.-Amsterdam 174: 105111, 2014.

Xu Y.H., Liu R., Yan L. et al.: Light-harvesting chlorophyll $a / b$ binding proteins are required for stomatal response to abscisic acid in Arabidopsis. - J. Exp. Bot. 63: 1095-1106, 2012.

Yang K., Rong W., Qi L. et al.: Isolation and characterization of a novel wheat cysteine-rich receptor-like kinase gene induced by Rhizoctonia cerealis. - Sci. Rep.-UK 3: 3021, 2013.

Zarepour M., Simon K., Wilch M. et al.: Identification of superoxide production by Arabidopsis thaliana aldehyde oxidases AAO1 and AAO3. - Plant Mol. Biol. 80: 659-671, 2012.

Zhang Y., Liu Q., Zhang Y. et al.: LMM24 encodes receptorlike cytoplasmic kinase 109, which regulates cell death and defense responses in rice. - Int. J. Mol. Sci. 20: 3243, 2019.

Zhao S.J., Xu Z.C., Zou Q. et al.: [Improvement of method for measurement of malondialdehyde in plant tissues.] - Plant 
Physiol. Commun. 30: 207-210, 1994. [In Chinese with English abstract]

Zhao Y., Wu G., Shi H., Tang D.: RECEPTOR-LIKE KINASE 902 associates with and phosphorylates BRASSINOSTEROIDSIGNALING KINASE1 to regulate plant immunity. - Mol. Plant 12: 59-70, 2019.

Zhou H., Li S., Deng Z. et al.: Molecular analysis of three new receptor-like kinase genes from hexaploid wheat and evidence for their participation in the wheat hypersensitive response to stripe rust fungus infection. - Plant J. 52: 420-434, 2007.

Zhou Y.B., Liu C., Tang D.Y. et al.: The receptor-like cytoplasmic kinase STRK1 phosphorylates and activates CatC, thereby regulating $\mathrm{H}_{2} \mathrm{O}_{2}$ homeostasis and improving salt tolerance in rice. - Plant Cell 30: 1100-1118, 2018.

(C) The authors. This is an open access article distributed under the terms of the Creative Commons BY-NC-ND Licence. 